\title{
REMUNERAÇÃO DOS EXECUTIVOS E INDICADORES DE DESEMPENHO EM EMPRESAS PARTICIPANTES DO IBOVESPA
}

Executive compensation and performance indicators in companies participating in the Bovespa Index

Régis Barroso Silva

E-mail: regis.silva@alu.ufc.br Mestre em Administração e Controladoria pela Universidade Federal do Ceará; Graduado em Administração de Empresas pela Faculdade Cearense; Coordenador Adjunto do NIT do Centro Universitário Christus. https://orcid.org/0000-0002-3749-6199

David Stanhy de Carvalho Silva

E-mail: davidstanhy@gmail.com Mestre em Administração e Controladoria pela Universidade Federal do Ceará; Especialista em Gestão de Pessoas pela Universidade Estadual do Piauí; Professor Assistente na Universidade Estadual do Piauí - Campus Rio Marataoan. https://orcid.org/0000-0002-9368-6704

Márcia Martins Mendes De Luca

E-mail: marciammdeluca@gmail.com

Doutora em Controladoria e Contabilidade pela Universidade de São Paulo; Mestre em Controladoria e Contabilidade pela Universidade de São Paulo; Professora na Faculdade de Economia, Administração Atuária e Contabilidade no Departamento de Contabilidade da Universidade Federal do Ceará. Endereço para contato: Avenida da Universidade, 2486, Benfica, 60020-180, Fortaleza, Ceará, Brasil. https://orcid.org/0000-0002-9995-5637

\section{Alessandra Carvalho de Vasconcelos}

E-mail: alevasconcelos.ufc@gmail.com Doutora em Engenharia de Produção pela Universidade Federal de Santa Catarina; Mestre em Ciências Contábeis pela Fundação Universidade Regional de Blumenau; Professora na Faculdade de Economia, Administração Atuária e Contabilidade no Departamento de Contabilidade da Universidade Federal do Ceará. https://orcid.org/0000-0002-6480-5620

Artigo recebido em 22 de março de 2018. Aceito em 05 de novembro de 2018. 


\title{
Resumo
}

Fundamentado na Teoria da Agência, neste estudo teve-se por objetivo principal analisar a relação entre a remuneração dos gestores de 48 empresas participantes do Ibovespa e seus indicadores de desempenho, utilizando-se dos testes de correlação, análise de correspondência múltipla e regressão. Os resultados evidenciaram a inexistência de correlação significante entre a remuneração dos diretores-executivos e os indicadores Lucro por Ação e Retorno sobre o Patrimônio Líquido. Embora os níveis de significância encontrados para a correlação entre remuneração dos diretoresexecutivos e desempenho apontem para a existência de correlação somente para os indicadores $Q$ de Tobin e a variação do Valor de Mercado, destaca-se a necessidade de continuidade dos estudos sobre o tema, uma vez que, em razão da separação da propriedade e controle e dos consequentes conflitos de agência entre proprietários e gestores, as empresas precisam adotar mecanismos para que o alinhamento entre esses agentes possibilite a criação de oportunidades que possam potencializar seus resultados.

Palavras-chave: Teoria da Agência. Remuneração de gestores. Indicadores de desempenho.

\begin{abstract}
According to the Agency Theory, the present study aims at analyzing the relation between remuneration for managers of 48 companies listed on the Bovespa Index and their respective performance indicators. This research employed the correlation, the multiple correspondence analysis and regression tests. The obtained results made it possible to verify the inexistence of significant correlation between the remuneration of managers and the performance indicators Earnings per share and Return on equity. Although the levels of significance found for the correlation between the variables executive compensation and performance indicators point at the existence of correlation only for Tobin's $Q$ and Market value variation, the continuity of studies stands out because, it is known that, due to the separation of property from control and resulting agency conflicts between owners and managers, companies need to adopt devices so that the alignment of these agents makes it possible to create opportunities to boost results.
\end{abstract}

Keywords: Agency Theory. Executive compensation. Performance indicators.

\section{INTRODUÇÃO}

A segregação entre propriedade e controle empresarial gera poder discricionário, que pode ser usado no favorecimento do gestor, em detrimento dos interesses do acionista, possibilitando conflitos de interesses que podem ser explicados pela inexistência de um contrato completo (Klein, 1984) e/ou de um agente perfeito (Jensen \& Meckling, 1976).

Também chamados de conflitos de agência, esses conflitos de interesses podem ser parcialmente reduzidos por meio do estabelecimento de contratos nos quais o acionista/principal proporciona aos gestores/agentes incentivos para que estes tomem decisões que influenciem a maximização da riqueza da corporação, destacando-se, entre eles, a remuneração (Jensen \& Meckling, 1976). Verifica-se, assim, que a remuneração dos executivos está no centro das discussões sobre os conflitos de interesses e que a Teoria da Agência sugere a existência de um contrato de 
remuneração baseado no desempenho, para que haja uma maior retenção e motivação dos gestores com relação aos objetivos traçados pelos acionistas (Ferrarini \& Moloney, 2005).

Além de fatores extrínsecos à organização, como o mercado e a economia, observa-se ainda que o desempenho organizacional é impactado pela forma como os gestores administram o negócio, razão pela qual é importante que estes sejam influenciados a selecionar e implementar ações em favor do principal (Beuren, Silva, \& Mazzioni, 2014).

Dessa forma, nota-se que o sistema de remuneração faz parte da estratégia organizacional, favorecendo o alinhamento entre os interesses dos acionistas e os dos gestores na busca pelo desempenho ótimo. O monitoramento do desempenho empresarial surge, portanto, como uma forma de estabelecimento de contratos de remuneração (Beurenet al., 2014).

Nesse contexto, propõe-se o seguinte questionamento de pesquisa: qual a correlação entre a remuneração dos gestores e o desempenho empresarial? Lastreada por estudos anteriores que analisaram a relação entre a remuneração e o desempenho empresarial (Aguiar \& Pimentel, 2017; Beuren et al., 2014; Camargos \& Helal, 2007; Degenhart, Martins, \& Hein, 2017; Demsetz \& Villalonga, 2001; Eulerich \& Velte, 2014; Forti, Barboza, Ribeiro, \& Nogueira, 2018; Funchal \& Terra, 2006; Himmelberg, Hubbard, \& Palia, 1999; Nascimento, Franco, \& Cherobim, 2012), na presente pesquisa considera-se a hipótese de que a remuneração dos diretores-executivos tem correlação positiva com os indicadores de desempenho empresarial, diferenciando-se das pesquisas já realizadas ao descreverem também o perfil desses gestores.

Neste estudo tem-se, portanto, o objetivo geral de identificar a correlação entre a remuneração dos gestores das empresas participantes do Índice Bovespa (lbovespa) e os respectivos indicadores de desempenho. Adicionalmente, buscou-se conhecer o perfil da diretoria executiva das empresas objeto de estudo, considerando gênero, faixa etária, profissão e cargo dos executivos.

Metodologicamente, o estudo é descritivo e de natureza quantitativa, investiga a correlação entre as variáveis remuneração dos executivos e indicadores de desempenho em 48 empresas participantes do lbovespa, posição da carteira de agosto de 2018. Levando em conta o conflito de interesses entre principal e agente (Teoria da Agência), na pesquisa consideraram-se os seguintes indicadores de desempenho, selecionados a partir da perspectiva do investidor acionista: valor de mercado (Camargos \& Helal, 2007; Funchal \& Terra, 2006); Q de Tobin (Beuren et al., 2014; Funchal \& Terra, 2006); lucro por ação (Camargos \& Helal, 2007; Nascimento, Barbosa, Cunha, \& Dias, 2011); e Retorno sobre o Patrimônio Líquido (Return on Equity (ROE)) (Beuren et al., 2014; Funchal \& Terra, 2006). São analisadas também características empresariais como tamanho, setor econômico e controle acionário das empresas da amostra. Fez-se uso dos testes de correlação de Pearson, de análise de correspondência múltipla e de regressão linear para verificar a relação entre as variáveis do estudo.

Sabe-se que a literatura sobre a temática já demonstra a relação entre a remuneração dos gestores e os indicadores de desempenho, tamanho e segmento de mercado das empresas. Entretanto, ainda é incipiente a oferta de estudos que apresentam um panorama investigativo para o perfil desses executivos, apesar de sua importância estratégica como responsáveis pelo 
alcance das metas da empresa. Além disso, vale destacar a relevância da discussão sobre o tema remuneração dos administradores, considerado uma questão sensível no processo de convergência entre os objetivos da gestão e os dos proprietários, com a finalidade principal de maximizar o desempenho e o valor da empresa (Brealey, Myers, \& Allen, 2011; Rodrigues \& Seabra, 2011).

Considerando esses aspectos, aprofunda-se a discussão sobre o relacionamento entre remuneração de executivos e desempenho. Para tanto, descreve-se o perfil dos executivos das empresas, informação não explorada em outros estudos, além do uso de distintas métricas para o desempenho empresarial, tais como a variação do Valor de Mercado, Q de Tobin, Lucro por Ação e Return On Equity (ROE), buscando investigar a associação entre a remuneração da diretoria executiva, o tamanho e o controle acionário das empresas, diferenciando-se dos demais trabalhos nacionais sobre o tema.

\section{FUNDAMENTAÇÃO TEÓRICA}

\subsection{TEORIA DA AGÊNCIA E REMUNERAÇÃO}

As grandes corporações estruturaram-se com a figura do proprietário como tomador de decisões sobre o seu próprio negócio, mas percebe-se que as organizações modernas, que surgiram da evolução do mercado, apresentam entes distintos para as funções de propriedade e controle (gestão do negócio), ou seja, o proprietário do capital e os gestores, respectivamente. As relações entre esses atores, em especial os seus conflitos, constituem o objeto de estudo da Teoria da Agência.

A Teoria da Agência reflete-se, portanto, no conflito de interesses existente entre esses atores (Jensen \& Meckling, 1976; Klein, 1984) e pode ser definida como a relação entre duas pessoas, em que uma delas (principal) delega à outra (agente) tarefas para serem desempenhadas em favor da primeira.

Segundo Jensen e Meckling (1976), os problemas de agência surgem com a separação entre a propriedade e o controle, podendo ser explicados pela questão essencial presente entre as partes: a maximização de resultados, do interesse de ambos.

A relação de agência demonstra que os acionistas arcam com dispêndio de recursos para capitalização do negócio e são focados na maximização de sua riqueza, enquanto os gestores, com amplo conhecimento sobre negócios, são focados na maximização de resultados, visando à sua remuneração (Rossetti \& Andrade, 2014).

Nesse contexto, as perdas residuais são resultado da não resolução dos conflitos de agência. Os custos de agência incluem os gastos para constatação de que o agente não agiu de forma oportunista. Entretanto, os conflitos entre principal e agente não são perfeitamente solucionados por esses custos em razão da ocorrência das perdas residuais, que representam a riqueza que os acionistas deixam de ganhar em decorrência de decisões inadequadas dos gestores (Jensen \& Meckling, 1976). 
O processo decisório da alta gestão contempla quatro etapas, cujas atribuições são divididas entre o conselho de administração e a diretoria executiva (foco dessa investigação), ficando para o conselho a ratificação das decisões relevantes, o monitoramento da alta gestão, a geração de propostas e a execução das decisões, de responsabilidade da diretoria executiva (Fama \& Jensen, 1983).

A oferta de sistemas de incentivos surge como uma tentativa de minimizar os conflitos de agência recompensando os gestores, e, com isso, melhorando o desempenho econômico (Souza, Cardoso, \& Vieira, 2017). Logo, esses sistemas de incentivos são oferecidos aos gestores como parte da estratégia para o alinhamento de interesses entre gestores e acionistas, visando alcançar os objetivos organizacionais (Anthony \& Govindarajan, 2008; Gonzaga, Yoshinaga, \& Eid, 2013).

No contexto da Teoria da Agência nota-se que os acionistas devem instituir incentivos permanentes no sentido de tornar a remuneração dos administradores cada dia mais atraente e competitiva (Camargos \& Helal, 2007). Para Nascimento et al. (2011) a compensação salarial é definida como a forma por meio da qual o contratante compensa o contratado com o objetivo de aumentar a sua satisfação, recrutar melhores empregados, retê-los e aumentar a sua lealdade com a empresa.

A Instrução Normativa n. 480, da Comissão de Valores Mobiliários (2009), dispõe sobre a evidenciação da política de remuneração dos administradores por meio do Formulário de Referência, definindo cinco modalidades de remuneração, a saber: fixa, variável, benefícios pós-emprego, benefícios motivados pela cessação do exercício do cargo e remuneração baseada em ações.

Entre as modalidades supracitadas, destaca-se que a parcela fixa da remuneração é, segundo Nascimento et al. (2011, p. 5), "aquela que o executivo recebe de forma constante e previamente acordada", e a remuneração variável é definida por Marcon e Godoi (2004) como o pagamento de valores indefinidos, condicionados ao cumprimento de determinadas metas, que geralmente são vinculadas a indicadores contábeis, econômicos, estratégicos e de mercado.

Nesse sentido, espera-se que haja comprometimento do gestor com os objetivos da organização, mediante seu envolvimento ativo e com foco no alcance de resultados empresariais satisfatórios. Destarte, a adoção de programas motivacionais tende a contribuir para criar um clima organizacional que propicie melhor desempenho empresarial e profissional (Nascimento et al., 2012). Considerase, portanto, que a melhoria dos resultados das empresas que adotam políticas diferenciadas de remuneração se reflete também em sua lucratividade, no retorno sobre o ativo, no retorno sobre o investimento, e, inclusive, afeta positivamente o valor das ações (Teixeira \& Loiola, 2006).

\subsection{ESTUDOS EMPÍRICOS E CONSTRUÇÃO DA HIPÓTESE DA PESQUISA}

Tratando-se da relação entre desempenho e remuneração, Camargos e Helal (2007) examinaram a correlação entre o desempenho organizacional e a remuneração dos gestores em empresas brasileiras com ações listadas em bolsas norte-americanas. Os autores encontraram uma correlação estatisticamente significante entre a remuneração executiva e o desempenho financeiro 
das empresas, sinalizando que os pacotes de compensação de gestores estão diretamente associados ao bom desempenho organizacional.

Nascimento et al. (2011) pesquisaram a existência de desempenho superior nas empresas brasileiras listadas na BM\&FBovespa cujas políticas de remuneração incluíam planos de opção por ações. As evidências apontaram que as empresas que optaram pela concessão de ações apresentaram um desempenho inferior, quando comparadas com aquelas que não concediam stock options.

A correlação entre a remuneração e o tamanho das organizações foi analisada por Conyon e Murphy (2000), em um estudo comparativo entre empresas do Reino Unido e dos Estados Unidos, concluindo-se que em ambos os países o tamanho da organização é fator determinante na remuneração dos executivos. No mesmo raciocínio, Toms e Wright (2002) compararam remuneração, tamanho das organizações e governança corporativa em empresas britânicas, no período de 1950 a 2000, encontrando correlação positiva entre essas variáveis.

Em pesquisa com companhias abertas da América Latina que possuíam ações negociadas nas bolsas de valores de Nova lorque e de Nasdaq, durante o ano 2002, Funchal e Terra (2006) concluíram que o setor de atividade é importante influenciador na remuneração dos administradores. Beuren et al. (2014) também realizaram uma pesquisa relacionando remuneração e desempenho, concluindo que o setor tem correlação positiva com a remuneração.

Sobre a relação entre remuneração e controle acionário, os estudos de Demsetz e Villalonga (2001) e Himmelberg et al. (1999), em empresas de vários setores econômicos dos Estados Unidos concluíram que não existe correlação direta entre a estrutura de capital das organizações e a remuneração dos seus gestores.

Entretanto, Theiss e Beuren (2014) verificaram que existe diferença entre a remuneração de executivos de acordo com a identidade do maior acionista controlador, no contexto de empresas com controle acionário institucional, estrangeiro, estatal ou familiar. No seu estudo, Anjos, Tavares, Monte, e Lustosa (2015) analisaram se o controle acionário poderia ser um fator determinante da remuneração dos executivos e concluíram que empresas com controle acionário mais disperso remuneram melhor seus executivos.

Mais recentemente, Souza et al. (2017) verificaram a relação dos determinantes da remuneração dos executivos com o desempenho financeiro e de mercado de 228 companhias brasileiras de capital aberto. Os autores utilizaram o teste de regressão linear múltipla, com dados em painel, para testar a relação entre remuneração e desempenho das companhias entre os anos 2011 e 2013. Destaca-se que os resultados dos testes estatísticos indicam que há relação positiva e significativa do desempenho financeiro com as remunerações baseadas em indicadores financeiros e não financeiros, em conjunto, e remunerações baseadas apenas em indicadores não financeiros. Entretanto, isso não ocorreu na análise do desempenho de mercado com a remuneração dos executivos, sinalizando que os planos de remuneração não alinham os interesses do principal e do agente.

Na mesma linha de pensamento, Degenhart et al. (2017) analisaram se há relação entre o desempenho econômico-financeiro e a remuneração dos diretores-executivos de 219 empresas 
brasileiras nos anos de 2011 a 2015. Para a análise dos dados, os autores utilizaram a análise de correlação de Spearman e a Regressão Linear, a partir das variáveis Retorno sobre o Ativo (ROA), Retorno sobre o Patrimônio Líquido (ROE), Tamanho da empresa (TAM), Market to Book (MB), Liquidez Geral (LG) e Lucro por Ação (LA). Em linhas gerais, os resultados indicam relação significativa e positiva entre o ROA e o Tamanho da empresa e a Remuneração Fixa, Variável e Total dos diretores-executivos.

A partir de dados secundários obtidos no Formulário de Referência de 333 empresas listadas na BM\&FBovespa, entre 2011 e 2015, Aguiar e Pimentel (2017) analisaram a relação entre remuneração e desempenho e constataram, por meio de regressão linear, que há relação entre remuneração e desempenho financeiro e de mercado das empresas. Além disso, os resultados indicam que os incrementos na remuneração tendem a gerar melhores desempenhos futuros e que há, inclusive, relação bidirecional entre remuneração e desempenho.

Com abordagem especificamente relacionada à utilização de planos de opções por ações (stock options) em 100 companhias brasileiras listadas na BM\&FBovespa. Oliveira e Silva (2018) buscaram identificar os determinantes econômicos que influenciam na concessão de stock options a partir de hipóteses concernentes ao desempenho financeiro e valor corporativo, ao endividamento, à concentração acionária e ao tamanho. Considerando o período de 2010 a 2015 na aplicação da regressão logística em painel, os autores constataram que quanto maior o desempenho financeiro menor é a probabilidade de uso de opções por ações, e que quanto menor a empresa maior a probabilidade de uso de opções de ações em seus planos de incentivos aos executivos. Adicionalmente, os resultados sinalizam que a concentração acionária também se relaciona negativamente com o uso de opções por ações, e há ausência de relação entre o endividamento e o uso de opções por ações. Em outras palavras, os autores concluem que o uso de opções por ações tende a ser utilizado por companhias de menor porte, com menor concentração acionária e de desempenho financeiro menor.

Em uma perspectiva mais específica, utilizando apenas os bancos brasileiros, Forti et al. (2018) investigaram a relação entre os incentivos financeiros pagos a funcionários e a rentabilidade. A amostra do estudo reúne todos os bancos em operação entre 2001 e 2011 que reportaram pagamento de participação nos lucros. Para tanto, os autores utilizaram como variável dependente o Retorno Sobre os Ativos (ROA). No caso, a variável de interesse buscou medir a intensidade percebida pelos funcionários do incentivo financeiro proporcionado pelo pagamento de participação nos lucros. Os resultados confirmam a hipótese de relação positiva e significante entre os incentivos financeiros e O ROA dos bancos.

Destarte, o Quadro 1 apresenta uma síntese dos estudos correlatos levantados na revisão de literatura. 
Tabela 1

Estudos empíricos anteriores sobre a temática remuneração de executivos

\begin{tabular}{|c|c|c|c|}
\hline Relação investigada & Estudos empíricos & Empresas analisadas & Resultado da relação \\
\hline \multirow{8}{*}{$\begin{array}{l}\text { Remuneração de } \\
\text { executivos versus } \\
\text { desempenho em- } \\
\text { presarial }\end{array}$} & Camargos e Helal (2007) & $\begin{array}{l}29 \text { empresas brasileiras com ações lis- } \\
\text { tadas em bolsas norte-americanas em } \\
2005 .\end{array}$ & Significante e Positiva \\
\hline & Beuren et al. (2014) & $\begin{array}{l}219 \text { empresas brasileiras de capital aber- } \\
\text { to entre } 2009 \text { e } 2011 \text {. }\end{array}$ & Significante e Positiva \\
\hline & Degenhart et al. (2017) & $\begin{array}{l}27 \text { empresas brasileiras listadas na BM\&- } \\
\text { FBovespa entre } 2010 \text { e } 2012 \text {. }\end{array}$ & $\begin{array}{l}\text { Significante e Positiva } \\
\text { para o ROA }\end{array}$ \\
\hline & Aguiar e Pimentel (2017) & $\begin{array}{l}333 \text { empresas brasileiras listadas na BM\&- } \\
\text { FBovespa entre } 2011 \text { e } 2015 \text {. }\end{array}$ & $\begin{array}{l}\text { Significante e Positiva } \\
\text { para o desempenho } \\
\text { financeiro e de mer- } \\
\text { cado }\end{array}$ \\
\hline & Souza et al. (2017) & $\begin{array}{l}228 \text { companhias brasileiras de capital } \\
\text { aberto entre } 2011 \text { e } 2013 \text {. }\end{array}$ & $\begin{array}{l}\text { Significante e Positiva } \\
\text { para o desempenho } \\
\text { financeiro e Significan- } \\
\text { te e Negativa para o } \\
\text { desempenho de mer- } \\
\text { cado }\end{array}$ \\
\hline & Forti et al. (2018) & 167 bancos brasileiros entre 2001 e 2011 . & $\begin{array}{l}\text { Significante e Positiva } \\
\text { para o ROA }\end{array}$ \\
\hline & Nascimento et al. (2012) & $\begin{array}{l}49 \text { empresas brasileiras listadas na BM\&- } \\
\text { FBovespa em } 2009 \text {. }\end{array}$ & Significante e Negativa \\
\hline & Oliveira e Silva (2018) & $\begin{array}{l}100 \text { companhias brasileiras listadas na } \\
\text { BM\&FBovespa entre } 2010 \text { e } 2015 .\end{array}$ & Significante e Negativa \\
\hline \multirow{3}{*}{$\begin{array}{l}\text { Remuneração de } \\
\text { executivos versus } \\
\text { controle acionário } \\
\text { ou concentração } \\
\text { acionária }\end{array}$} & Theiss e Beuren (2014) & $\begin{array}{l}172 \text { companhias brasileiras listadas na } \\
\text { BM\&FBovespa que evidenciaram a re- } \\
\text { muneração dos executivos no Formulário } \\
\text { de Referência entre } 2009 \text { e } 2011 \text {. }\end{array}$ & Significante \\
\hline & Anjos et al. (2015) & $\begin{array}{l}144 \text { empresas brasileiras listadas na BM\&- } \\
\text { FBovespa entre } 2011 \text { e } 2013 \text {. }\end{array}$ & Significante \\
\hline & Oliveira e Silva (2018) & $\begin{array}{l}100 \text { companhias brasileiras listadas na } \\
\text { BM\&FBovespa entre } 2010 \text { e } 2015 \text {. }\end{array}$ & Significante \\
\hline \multirow{4}{*}{$\begin{array}{l}\text { Remuneração de } \\
\text { executivos versus ta- } \\
\text { manho da empresa }\end{array}$} & Conyon e Murphy (2000) & $\begin{array}{l}510 \text { empresas do Reino Unido e } 1.666 \\
\text { empresas dos Estados Unidos em } 1997 .\end{array}$ & Significante e Positiva \\
\hline & Toms e Wright (2002) & $\begin{array}{l}2.356 \text { empresas britânicas entre } 1950 \text { e } \\
2000 \text {. }\end{array}$ & Significante e Positiva \\
\hline & $\begin{array}{l}\text { Degenhart, Martins, e Hein } \\
\text { (2017) }\end{array}$ & $\begin{array}{l}27 \text { empresas brasileiras listadas na BM\&- } \\
\text { FBovespa entre } 2010 \text { e } 2012 \text {. }\end{array}$ & Significante e Positiva \\
\hline & Oliveira e Silva (2018) & $\begin{array}{l}100 \text { companhias brasileiras listadas na } \\
\text { BM\&FBovespa entre } 2010 \text { e } 2015 \text {. }\end{array}$ & Significante e Negativa \\
\hline $\begin{array}{l}\text { Remuneração de } \\
\text { executivos versus } \\
\text { setor de atuação }\end{array}$ & Funchal e Terra (2006) & $\begin{array}{l}67 \text { companhias abertas da América } \\
\text { Latina listadas na Nyse e na Nasdaq em } \\
2002 \text {. }\end{array}$ & Significante \\
\hline \multirow{2}{*}{$\begin{array}{l}\text { Remuneração de } \\
\text { executivos versus } \\
\text { estrutura de capital }\end{array}$} & $\begin{array}{l}\text { Himmelberg, Hubbard, e } \\
\text { Palia (1999) }\end{array}$ & $\begin{array}{l}881 \text { empresas dos Estados Unidos entre } \\
1982 \text { e } 1984 \text {. }\end{array}$ & $\begin{array}{l}\text { Não identificou rela- } \\
\text { ção significante }\end{array}$ \\
\hline & Demsetz e Villalonga (2001) & $\begin{array}{l}223 \text { empresas dos Estados Unidos entre } \\
1976 \text { e } 1980 .\end{array}$ & $\begin{array}{l}\text { Não identificou rela- } \\
\text { ção significante }\end{array}$ \\
\hline
\end{tabular}

Nota-se que a Tabela 1 evidencia que, apesar de não haver resultados consensuais entre os diferentes estudos sobre a relação entre a remuneração de executivos e os aspectos institucionais das empresas, tem-se recomendações da literatura para a construção da seguinte hipótese de pesquisa: existe correlação positiva entre a remuneração dos gestores das empresas listadas no Ibovespa e indicadores de desempenho. 
A seção seguinte apresenta os procedimentos adotados para investigar a existência de correlação entre a remuneração dos diretores-executivos e o desempenho empresarial nas empresas participantes do lbovespa, descrever o perfil da diretoria executiva e verificar a existência de correspondência entre remuneração da diretoria executiva, tamanho e controle acionário das empresas.

\section{PROCEDIMENTOS METODOLÓGICOS}

O universo amostral constituiu-se de empresas listadas no lbovespa, posição em agosto de 2018, com informações dos exercícios sociais de 2014 a 2017 extraídas da base de dados Economática, totalizando inicialmente 60 diferentes companhias.

Admitindo-se a existência de características específicas nas empresas do segmento financeiro, estas foram excluídas com o objetivo de evitar distorções nos resultados finais, seguindose a mesma técnica adotada por Beuren et al. (2014). Além disso, foi observado que algumas empresas possuíam dois tipos de ações na carteira selecionada e para os itens duplicados se optou por selecionar a ação mais líquida para análise. Também foram excluídas as empresas que não divulgaram informações sobre a remuneração da diretoria, objeto do item 13 do Formulário de Referência, disponível no website da B3 S.A. - Brasil, Bolsa, Balcão.

A amostra da pesquisa, extraída dessa população, constituiu-se, portanto, de 48 empresas que fazem parte do lbovespa, não participantes do segmento financeiro, as quais apresentaram informações disponíveis na base de dados Economática e que divulgaram as informações completas sobre remuneração da diretoria no Formulário de Referência.

Buscando testar a hipótese formulada para a pesquisa, utilizam-se as técnicas estatísticas de correlação, análise de correspondência múltipla e regressão linear. Inicialmente, optou-se pela realização do teste paramétrico de Correlação de Pearson, já que a amostra foi originada de uma população com distribuição normal, cuja constatação foi feita pelo teste de Kolmogorov-Smirnov, ao nível de significância de $5 \%$.

Posteriormente, a análise de regressão linear múltipla foi aplicada com o intuito de verificar a relação de dependência, ou seja, a influência da remuneração na formação do desempenho.

Já a investigação das relações de proximidade entre a remuneração dos gestores e as características empresariais selecionadas foi realizada por meio da análise de correspondência múltipla, possibilitando a associação de variáveis qualitativas em razão dos seus níveis e graus de complexidade. Para Fávero, Belfiore, Silva, e Chan (2009), esse procedimento possibilita analisar as correspondências de mais de duas variáveis com diferentes números de níveis.

A Tabela 2 mostra os indicadores de desempenho utilizados na pesquisa. 
Tabela 2

Indicadores de desempenho empresarial utilizados na pesquisa

\begin{tabular}{|c|c|c|c|}
\hline Variável & Mensuração & Descrição & Fundamentação teórica \\
\hline $\begin{array}{l}\text { Variação do Valor } \\
\text { de Mercado }\end{array}$ & $\begin{array}{l}\text { Diferença entre o Valor de Mer- } \\
\text { cado do ano analisado e o do } \\
\text { ano anterior }\end{array}$ & $\begin{array}{l}\text { Demonstra o quanto variou o } \\
\text { Valor de Mercado da empresa } \\
\text { entre TO e Tl }\end{array}$ & $\begin{array}{l}\text { Camargos e Helal (2007) } \\
\text { Funchal e Terra (2006) }\end{array}$ \\
\hline Q de Tobin & $\begin{array}{l}\text { (Valor de Mercado + Dívidas)/ } \\
\text { Ativo total }\end{array}$ & $\begin{array}{l}\text { Relação entre o Valor de Merca- } \\
\text { do total da empresa e o Valor do } \\
\text { seu Ativo }\end{array}$ & $\begin{array}{l}\text { Beuren et al. (2014) } \\
\text { Funchal e Terra (2006) }\end{array}$ \\
\hline Lucro por Ação & Lucro líquido/Número de ações & $\begin{array}{l}\text { Mede o lucro líquido pertencente } \\
\text { a cada ação }\end{array}$ & $\begin{array}{l}\text { Camargos e Helal (2007) } \\
\text { Nascimento et al. (2011) }\end{array}$ \\
\hline $\begin{array}{l}\text { Return On Equity } \\
\text { (ROE) }\end{array}$ & Lucro líquido/Patrimônio líquido & $\begin{array}{l}\text { Mede o retorno sobre o Patrimô- } \\
\text { nio Líquido }\end{array}$ & $\begin{array}{l}\text { Beuren et al. (2014) } \\
\text { Funchal e Terra (2006) }\end{array}$ \\
\hline
\end{tabular}

Além da descrição da operacionalização dos indicadores empresariais, que foram selecionados a partir da perspectiva do acionista, a Tabela 2 aponta os estudos empíricos que os utilizaram anteriormente.

Neste estudo, a remuneração da diretoria executiva de cada empresa é representada pela divisão do total da remuneração variável divulgada no item 13 do respectivo Formulário de Referência e pelo número de membros da diretoria executiva, calculando-se posteriormente a diferença entre essas remunerações entre os anos analisados. Destaca-se que proxy semelhante foi adotada nos estudos de Aguiar e Pimentel (2017) e Degenhart et al. (2017). Para a efetivação da análise de correspondência múltipla os valores encontrados foram anteriormente segmentados em dados não métricos, por meio de quartis, para possibilitar a realização da análise de correspondência, obtendo-se os quatro níveis de remuneração, a saber: alto, médio/ alto, médio/baixo e baixo.

Quanto ao perfil da diretoria executiva das empresas da amostra, destaca-se que as informações relativas a gênero, faixa etária, profissão e cargo dos executivos foram extraídas do item 12.6 do Formulário de Referência das empresas da amostra, disponível no website da B3 S.A.

Foram selecionadas as características empresariais tamanho (Conyon \& Murphy, 2000; Toms \& Wright, 2002; Degenhart et al., 2017) e controle acionário (Demsetz \& Villalonga, 2001; Himmelberg et al., 1999), já adotadas em estudos empíricos anteriores que encontraram a existência de associação com a remuneração dos gestores. Vale destacar que a pesquisa considerou ainda o setor de atividade das empresas segundo a classificação da B3 S.A. Para a variável tamanho, fez-se uso do logaritmo natural do Ativo Total, dividido e classificado em pequeno, médio e grande portes, por intermédio de tercis. Para se analisar o controle da empresa, foi utilizada a classificação adotada por Parente, Vasconcelos e De Luca (2014), a saber: estrangeiro, estatal, familiar e institucional.

O tratamento dos dados (correlação, análise de correspondência múltipla e regressão linear) foi realizado com o auxílio do aplicativo Statistical Package for the Social Sciences (SPSS), versão 22. 


\section{RESULTADOS E DISCUSSÃO}

\subsection{PERFIL DA DIRETORIA EXECUTIVA E CARACTERÍSTICAS EMPRESARIAIS}

A partir da análise das informações extraídas do item 12.6 do Formulário de Referência para as 48 empresas da amostra, foi possível observar que os membros das diretorias e dos conselhos de administração totalizam 1.234 diferentes pessoas entre os quatro anos estudados. Após a identificação destas, foram levantadas as informações relativas a gênero, faixa etária, profissão e cargo ocupado, com o propósito de conhecer a configuração da diretoria executiva nas empresas pesquisadas.

De acordo com os dados apresentados, observou-se uma grande quantidade de homens ocupantes de cargos nas diretorias executivas. O gênero masculino representou a maior parcela dos gestores analisados $(89,2 \%)$. Esses resultados corroboram os de Machado e Beuren (2015), segundo os quais, no Brasil, a esmagadora maioria dos gestores pertence ao gênero masculino, com tendências comportamentais agressivas para a tomada de decisões. Além disso, as autoras assinalam que as mulheres executivas apresentam características mais conservadoras e menos agressivas nas decisões. O estudo de Almeida, Klotzle, e Figueiredo (2013) também robustece a baixa participação feminina na composição da diretoria executiva e do conselho de administração, em cerca de 6,0\%.

No que tange à faixa etária, destaca-se que $74,8 \%$ dos executivos da amostra têm mais de 50 anos, sendo que o gestor mais jovem tem 25 anos. Dentre os gestores mais velhos do gênero masculino, apenas 19,3\% têm idade superior a 65 anos e o de maior idade tem 88 anos. Do gênero feminino, a gestora de maior idade tem 78 anos. Vale ressaltar, também, que praticamente metade dos membros da amostra $(50,8 \%)$ está no intervalo entre 50 e 70 anos. A média geral de idade dos administradores analisados é de 56,6 anos.

Na Tabela 3 observa-se que, dos 1.234 gestores, 33,7\% têm formação superior em cursos da área de Engenharia, 19,6\% são graduados em cursos da área da Administração e 11,0\% são formados em cursos da área do Direito. Ainda de acordo com o estudo de Machado e Beuren (2015), a formação dos executivos brasileiros mostrou um destaque maior para a área de Administração, enquanto a Engenharia estava mais presente na formação de executivos estadunidenses, de forma contrária aos resultados obtidos nesta pesquisa, quando comparados aos executivos brasileiros. É relevante ressaltar, ainda, que entre as outras formações apontadas na Tabela 3 (18\%), destacamse arquitetos, médicos, jornalistas, sociólogos, psicólogos, analistas de sistema, químicos e geólogos.

Tabela 3

Distribuição dos executivos brasileiros por área de formação acadêmica e cargo

\begin{tabular}{|c|c|c|c|c|c|c|c|c|}
\hline \multirow{2}{*}{ Área de Formação } & \multicolumn{6}{|c|}{ Cargo } & \multirow{2}{*}{ Total } & \multirow{2}{*}{$\%$} \\
\hline & Presidente & $\%$ & Vice-presidente & $\%$ & Outros & $\%$ & & \\
\hline Engenharias & 39 & 9,2 & 46 & 10,8 & 340 & 80,0 & 425 & 33,7 \\
\hline Administração & 29 & 11,9 & 18 & 7,5 & 196 & 80,6 & 243 & 19,6 \\
\hline Direito & 6 & 4,4 & 11 & 8,1 & 119 & 87,5 & 136 & 11,0 \\
\hline Economia & 4 & 2,5 & 15 & 9,0 & 147 & 88,5 & 166 & 13,4 \\
\hline Contabilidade & 1 & 2,6 & 2 & 4,8 & 38 & 92,6 & 41 & 4,3 \\
\hline Outros & 18 & 8,2 & 12 & 5,3 & 193 & 86,5 & 223 & 18,0 \\
\hline Total & 97 & 7,8 & 104 & 8,4 & 1033 & 83,8 & 1234 & 100,0 \\
\hline
\end{tabular}


Dentre os gestores das empresas da amostra, considerando-se o somatório dos dois gêneros, verificou-se que $7,9 \%$ ocupam cargos de presidência e $8,4 \%$ de vice-presidência. Foi possível verificar, ainda, que são variadas as nomenclaturas utilizadas para designar os diversos cargos que compõem as diretorias executivas da amostra. No grupo Outros, que corresponde a 83,7\% dos executivos, estão incluídos, por exemplo, Diretor-executivo de Desenvolvimento de Negócios, Diretor-executivo Operacional, Diretor-executivo Financeiro, Diretor-executivo de Controladoria e Diretor-executivo de Produção.

Quanto à formação acadêmica dos gestores analisados, sua totalidade concluiu o ensino superior, sendo que $96,2 \%$ possuem uma graduação, enquanto $3,8 \%$ possuem duas, confirmando as constatações de Machado e Beuren (2015), que encontraram 93,3\% de executivos com apenas uma formação. Dentre os gestores que possuem duas graduações, destaca-se a preferência pelas Ciências Sociais Aplicadas, a exemplo de quatro executivos formados em Administração e Ciências Contábeis, sete graduados em Administração e Economia e três bacharéis em Ciências Contábeis e Economia.

Em resumo, por meio do conjunto de dados coletados, e utilizando-se do Formulário de Referência de cada uma das empresas que foram alvo da pesquisa, constatou-se que o perfil da diretoria executiva nas empresas analisadas é caracterizado pela predominância de homens, com idade média de 56,6 anos e uma graduação, notadamente com formação em áreas da Engenharia e Administração.

A classificação por setor econômico e por controle acionário pode ser verificada na Tabela 4:

Tabela 4

Classificação das empresas por setor econômico e tipo de controle acionário

\begin{tabular}{|c|c|c|c|c|c|c|c|c|c|c|}
\hline \multirow{3}{*}{ Classificação setorial segundo a B3 S.A. } & \multicolumn{8}{|c|}{ Controle acionário } & \multirow{2}{*}{\multicolumn{2}{|c|}{ Total }} \\
\hline & \multicolumn{2}{|c|}{ Estatal } & \multicolumn{2}{|c|}{ Estrangeiro } & \multicolumn{2}{|c|}{ Familiar } & \multicolumn{2}{|c|}{ Institucional } & & \\
\hline & Qtd. & $\%$ & Qtd. & $\%$ & Qtd. & $\%$ & Qtd. & $\%$ & Qtd. & $\%$ \\
\hline Bens industriais & & & 1 & 2,1 & & & & & 1 & 2,1 \\
\hline Construção e transporte & & & & & 3 & 6,3 & 2 & 4,2 & 5 & 10,4 \\
\hline Consumo cíclico & & & 3 & 6,3 & 1 & 2,1 & 5 & 10,4 & 9 & 18,8 \\
\hline Consumo não cíclico & & & 2 & 4,2 & & & 5 & 10,4 & 7 & 14,6 \\
\hline Materiais básicos & 1 & 2,1 & 1 & 2,1 & & & 7 & 14,6 & 9 & 18,8 \\
\hline Petróleo, gás e biocombustíveis & 1 & 2,1 & & & & & 1 & 2,1 & 2 & 4,2 \\
\hline Saúde & & & 1 & 2,1 & & & 2 & 4,2 & 3 & 6,3 \\
\hline Telecomunicações & & & 1 & 2,1 & & & 1 & 2,1 & 2 & 4,2 \\
\hline Utilidade pública & 4 & 8,3 & 1 & 2,1 & & & 5 & 10,4 & 10 & 20,8 \\
\hline Total & 6 & 12,5 & 10 & 20,8 & 4 & 8,3 & 28 & 58,3 & 48 & 100,0 \\
\hline
\end{tabular}

Quanto ao estudo dos dados relacionados às características das empresas pesquisadas, pode-se inferir que se verifica uma concentração em nove setores, com a seguinte distribuição proporcional: utilidade pública (21,3\%), consumo cíclico $(19,1 \%)$, materiais básicos $(19,1 \%)$, consumo não cíclico (14,9\%), construção e transportes (10,6\%), saúde $(6,4 \%)$, telecomunicações 
(4,3\%), petróleo, gás e biocombustíveis $(2,1 \%)$ e bens industriais $(2,1 \%)$. É possível destacar, ainda, em relação ao controle acionário, que a maior parcela das empresas possui controle institucional $(37,5 \%)$, seguido pelos controles estatal $(33,3 \%)$, estrangeiro $(20,8 \%)$ e familiar $(8,4 \%)$.

Após a apresentação do perfil das diretorias executivas e das características econômicas das empresas, passou-se à aplicação dos testes para a análise quantitativa da relação entre a remuneração dos gestores, os indicadores de desempenho empresarial e as características das empresas, com a finalidade de testar a hipótese do estudo.

\subsection{ASSOCIAÇÃO ENTRE REMUNERAÇÃO DA DIRETORIA EXECUTIVA E CARACTERÍSTICAS EMPRESARIAIS}

Buscando identificar a relação entre a remuneração dos gestores e as características empresariais levantadas, a Figura 1 mostra o mapa perceptual com a representação da associação entre a remuneração, o tipo de controle acionário e o tamanho das empresas estudadas, obtido a partir da análise de correspondência múltipla, ou análise de homogeneidade (HOMALS).

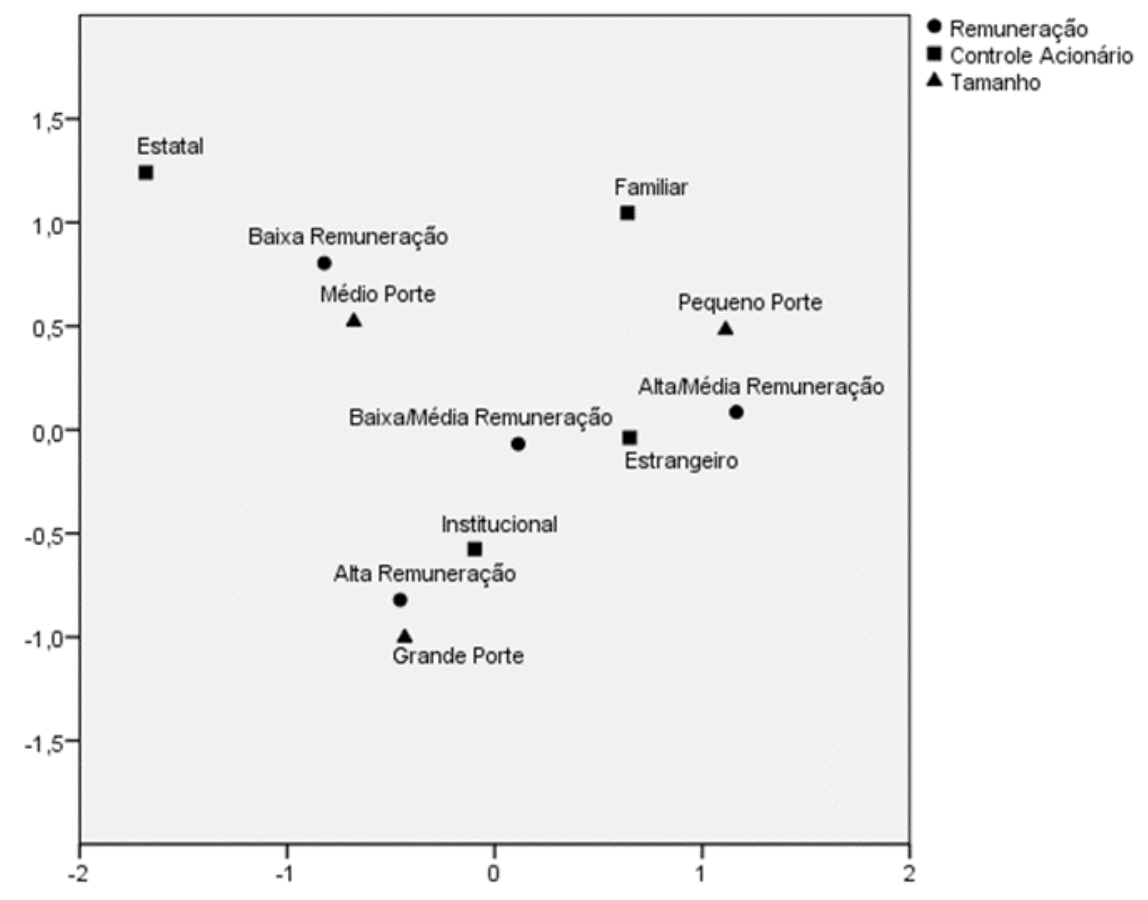

Figura 1. Mapa perceptual da Remuneração versus Controle Acionário versus Tamanho

Para um bom emprego da análise foram utilizadas as 48 companhias da amostra, podendose inferir a existência de associação entre empresas de grande porte e alta remuneração dos executivos. Esse resultado fica próximo aos achados de Degenhart et al. (2017), que investigaram 219 empresas brasileiras nos anos de 2011 a 2015, encontrando uma relação significativa e positiva entre o Tamanho da empresa e a Remuneração Fixa, Variável e Total dos diretores-executivos, indicando que as grandes empresas remuneram mais seus executivos do que as empresas menores. Por sua vez, o achado vai de encontro aos resultados de Oliveira e Silva (2018), que ao analisarem 
100 companhias brasileiras listadas na BM\&FBovespa concluíram que o uso de opções por ações ao executivo tende a ser feito por companhias de menor porte, contrariando a literatura preponderante sobre o tema. Além disso, a partir das informações evidenciadas na Figura 1, nota-se a existência de associação entre baixa remuneração dos executivos e empresas de médio porte. Ressalte-se que Conyon e Murphy (2000), Eulerich e Velte (2014), Funchal e Terra (2006) e Toms e Wright (2002) encontraram resultados semelhantes, em que o tamanho da empresa se mostra como um dos principais determinantes da remuneração dos administradores, encontrando-se, nesses estudos, correlações positivas e significativas entre essas variáveis.

Quanto à remuneração dos diretores e ao controle acionário das empresas, verifica-se uma associação entre alta remuneração e empresas de controle acionário institucional, assim como entre média alta e média baixa remuneração e controle acionário estrangeiro, divergindo das expectativas desta pesquisa, pois se esperava uma maior aproximação de elevada remuneração e controle estrangeiro. Contraditoriamente, Andreas, Rapp, e Wolff (2012) não encontraram correlação positiva entre propriedade institucional e remuneração nas empresas da Alemanha. Cabe advertir que os estudos nacionais de Anjos et al. (2015), Oliveira e Silva (2018) e Theiss e Beuren (2014), todos eles em companhias brasileiras listadas na Bolsa de Valores, concluíram que o controle acionário é um fator determinante da remuneração dos executivos e que há relação direta entre as variáveis, uma vez que identificaram que empresas com controle acionário mais disperso remuneram melhor seus executivos.

Com relação às outras características empresariais analisadas, não se pode inferir quaisquer associações em decorrências das dispersões apresentadas na Figura 1.

\subsection{CORRELAÇÃO ENTRE REMUNERAÇÃO DOS GESTORES E INDICADORES FINANCEIROS}

Diante da hipótese de pesquisa formulada, procurou-se identificar a correlação entre a remuneração dos executivos e as variáveis Variação do Valor de Mercado, $Q$ de Tobin, ROE e Lucro por Ação das 48 empresas da amostra. Os resultados da Correlação de Pearson podem ser observados na Tabela 5:

Tabela 5

Correlação entre remuneração e indicadores de desempenho

\begin{tabular}{|c|c|c|c|c|c|c|c|}
\hline \multirow[b]{2}{*}{ Remuneração } & \multicolumn{2}{|c|}{ Remuneração } & \multicolumn{2}{|c|}{$\begin{array}{l}\text { Variação do Valor } \\
\text { de Mercado }\end{array}$} & $Q$ de Tobin & \multirow[t]{2}{*}{ ROE } & \multirow[t]{2}{*}{$\begin{array}{l}\text { Lucro por } \\
\text { Ação }\end{array}$} \\
\hline & 1,000 & & & & & & \\
\hline Variação do Valor de Mercado & 0,184 & $(*)$ & 1,000 & & & & \\
\hline$Q$ de Tobin & 0,189 & $(* *)$ & 0,152 & $(*)$ & 1,000 & & \\
\hline $\mathrm{ROE}$ & $-0,095$ & & 0,079 & & 0,301 & 1,000 & \\
\hline Lucro por Ação & $-0,014$ & & $0,384\left(^{* *}\right)$ & & 0010 & $0,245\left(^{* *}\right)$ & 1,000 \\
\hline
\end{tabular}

A partir da Tabela 5, considerando-se um nível de significância de 5\%, pode-se inferir que nas empresas da amostra há uma correlação entre a remuneração dos executivos e $\circ Q$ de 
Tobin. Ao nível de significância de 10\%, constatou-se uma correlação entre a remuneração dos administradores e a Variação do Valor de Mercado. Quanto à relação entre a remuneração e o desempenho de mercado, destaca-se que ao analisarem 333 empresas listadas na BM\&FBovespa, Aguiar e Pimentel (2017) também identificaram relação significante e positiva entre as variáveis. Os resultados encontrados também se alinham com os achados da pesquisa realizada por Funchal e Terra (2006), que se utilizaram do $Q$ de Tobin, da Variação do Valor de Mercado e de outros indicadores de desempenho empresariais como determinantes da remuneração. Camargos e Helal (2007) também encontraram uma correlação estatisticamente significante entre a remuneração dos administradores e os principais indicadores de desempenho em empresas brasileiras com ações listadas em bolsas norte-americanas.

A análise da correlação entre a remuneração dos executivos, o Q de Tobin e a Variação do Valor de Mercado também foi objeto de pesquisa realizada por Beuren et al. (2014), que constataram uma correlação entre essas variáveis em 219 empresas brasileiras de capital aberto. Esses autores fizeram, ainda, um comparativo entre remuneração e outros indicadores financeiros (ROA, Lucro por Ação e Dividendos por Ação), não se revelando qualquer correlação, assim como na presente pesquisa, em que também não se encontrou correlação com o lucro por ação nem com o ROE. Conforme explanam Aguiar e Pimentel (2017), a relação não significativa entre a remuneração dos executivos e o longo prazo e desempenho financeiro, medido pelo ROE, pode ser explicada pelo fato de o retorno sobre o patrimônio líquido ser uma medida de desempenho passado e, portanto, de curto prazo.

Nesse sentido, é possível refutar a hipótese inicial da pesquisa, já que não foram encontrados indícios coerentes de correspondência entre a remuneração e os indicadores de desempenho selecionados. De forma similar, outros estudos também não encontraram correlação entre essas variáveis, como os de Funchal e Terra (2006), em que as variáveis indicadoras do desempenho das empresas latino-americanas não se mostraram relevantes para explicar a remuneração dos seus executivos. Nascimento et al. (2012) constataram uma reduzida ou nenhuma influência da prática de remuneração sobre os índices contábeis das empresas.

Diante dos resultados encontrados, procedeu-se, ainda, com a análise de correspondência múltipla entre a remuneração dos executivos e os indicadores que apresentaram correlação, considerando-se o teste de correlação apresentado na Tabela 5. A Figura 2 apresenta o mapa perceptual da associação entre remuneração dos gestores, $Q$ de Tobin e Valor de Mercado. 


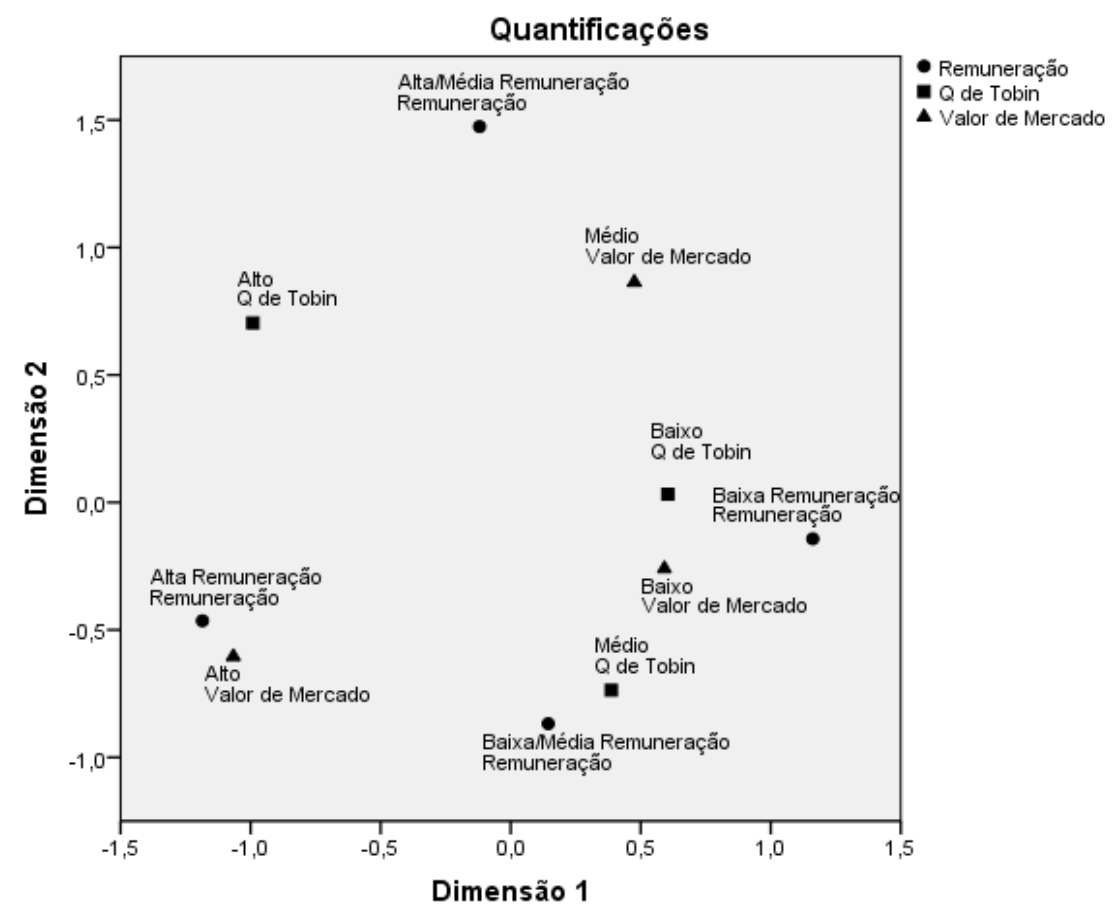

Figura 2. Mapa perceptual da Remuneração versus $Q$ de Tobin versus Valor de Mercado

Na Figura 2 é possível verificar indícios de associação entre alta remuneração dos diretoresexecutivos e empresas que apresentam uma elevada Variação do Valor de Mercado. Outra associação perceptível é entre média/baixa remuneração e médio $Q$ de Tobin. Esses resultados reforçam as constatações de Beuren et al. (2014), cujos achados indicam a ocorrência de alinhamento entre a remuneração dos gestores e esses indicadores.

Posteriormente foi realizada análise de regressão linear múltipla, considerando as variáveis do estudo, cujos resultados dos modelos são evidenciados na Tabela 6:

Tabela 6

Análise de regressão linear múltipla

\begin{tabular}{|c|c|c|c|c|c|}
\hline Modelos analisados & Modelo 1 & Modelo 2 & Modelo 3 & \multicolumn{2}{|c|}{ Modelo 4} \\
\hline Variável dependente: & VVM & Q de Tobin & ROE & LPA & \\
\hline Constante & $-1542006,587$ & 1,301 & 0,141 & $-2,122$ & * \\
\hline Remuneração total & 0,131 & 0,000 & 0,000 & 0,000 & \\
\hline Tamanho & $-90881,744$ & $-0,063$ & $-0,012$ & 0,326 & * \\
\hline$R$ & $18,40 \%$ & $20,20 \%$ & $10,50 \%$ & $16,30 \%$ & \\
\hline $\mathrm{R}^{2}$ & $3,40 \%$ & $4,10 \%$ & $1,10 \%$ & $2,70 \%$ & \\
\hline $\mathrm{F}$ & 3,259 & 3,938 & 1,035 & 2,545 & $* *$ \\
\hline
\end{tabular}

Preliminarmente à análise das variáveis é necessário analisar a significância dos modelos estatísticos a partir do teste F. Esse teste confirmou a significância dos modelos 1 e 2, ao nível de significância de 5\%, e o modelo 4 , ao nível de significância de $10 \%$. O modelo 3 não apresentou significância, indicando que as variáveis consideradas não possuem relação de dependência. A partir do valor do $R^{2}$ é possível inferir sobre o poder explicativo da regressão. 
O modelo 1 evidencia que a remuneração total influencia positivamente a constituição da Variação do Valor de Mercado das empresas. Tal achado também é percebido no modelo 2, em que a remuneração total se mostra fator determinante do $Q$ de Tobin. Já no modelo 4, apenas a variável Tamanho se apresenta como fator influenciador do LPA. Tais achados coadunam com aqueles revelados pela análise de correlação, contudo, na análise de regressão os resultados apresentam uma relação de dependência.

\section{CONSIDERAÇÕES FINAIS}

A remuneração dos gestores tem sido alvo de discussões, tanto no campo acadêmico quanto no campo empresarial, em especial no que tange aos conflitos de interesses entre administradores e proprietários, base da Teoria da Agência. Os sistemas de incentivos, entre eles a remuneração, são utilizados nesse contexto como uma forma de mitigar os conflitos de agência, por meio de recompensas para os gestores (agentes) os quais tomam decisões que maximizam o valor da organização para os acionistas (principal).

Com fundamento na Teoria da Agência, na presente pesquisa teve-se como objetivo geral analisar a correlação entre o valor da remuneração dos gestores das empresas participantes do Ibovespa e seus principais indicadores de desempenho. Para tanto, foram levantadas informações qualitativas e quantitativas, referentes aos exercícios sociais de 2014 a 2017, por meio do Formulário de Referência de 48 empresas do Ibovespa (posição em agosto de 2018), disponibilizadas pela B3 S.A. e pela correspondente base de dados Economática. A análise possibilitou confrontar algumas considerações sobre essa relação com estudos que já abordaram o tema em outros cenários.

Nos resultados obtidos pôde-se constatar que a configuração da diretoria executiva, mediante o perfil dos gestores das empresas não financeiras participantes do Índice Bovespa são, em sua maioria, do gênero masculino e pertencem à faixa etária de 50 a 70 anos. Verificou-se, ainda, que a maioria desses executivos possui formação acadêmica, sendo bastante representativo o grupo de diretores graduados em Engenharia. Constatou-se, ainda, que a maioria das empresas selecionadas para o estudo pertence aos setores Consumo não cíclico e Materiais básicos. Esses setores são responsáveis pela produção de alimentos processados e medicamentos, e abrangem as grandes empresas siderúrgicas e metalúrgicas. Foi possível perceber, ainda, uma predominância do controle acionário do tipo institucional, ou seja, a maioria das empresas analisadas é controlada por grandes organizações, bancos e fundos de investimentos.

Os resultados obtidos por meio da Correlação de Pearson possibilitaram inferir que nas empresas da amostra não há correlação entre a remuneração dos gestores e o desempenho, considerandose todos os indicadores empresariais selecionados. Os testes estatísticos apontaram uma correlação apenas entre a remuneração dos executivos, a Variação do Valor de Mercado e o $Q$ de Tobin, não havendo indícios de correlação com Lucro por Ação e ROE. Quanto à relação de influência, observou-se uma confirmação da análise de correlação na medida em que a remuneração se mostrou influenciar apenas os modelos nos quais a variável dependente foi a variação do Valor 
de Mercado e o $Q$ de Tobin, enquanto não sugeriu influenciar a formação do ROE e LPA. Quanto aos resultados obtidos por meio da análise de correspondência múltipla, foi possível inferir que há associação entre as empresas de médio porte e a baixa remuneração dos gestores. Percebeu-se, ainda, uma proximidade entre as empresas de grande porte e aquelas sob controle institucional, de tal forma que ambos os grupos se associam aos altos níveis de remuneração dos diretores-executivos.

A literatura sobre o tema que correlaciona a remuneração dos executivos com o desempenho empresarial traz conclusões bastante heterogêneas, de maneira que não se pode obter uma definição clara da existência dessa correlação. Os resultados encontrados neste estudo corroboram os achados de Funchal e Terra (2006), Nascimento et al. (2011) e Nascimento et al. (2012), que não obtiveram evidências estatísticas significativas para a correlação entre remuneração e desempenho empresarial, mas se coadunam com outros estudos que revelam a existência de correlação com indicadores de desempenho específicos (Beuren et al., 2014; Camargos \& Helal, 2007).

No contexto da Teoria da Agência o estudo contribui tanto para a área de conhecimento quanto para o meio empresarial, em especial, para o mercado de capitais. O tema remuneração dos diretores desponta como uma alternativa de estímulo para a redução dos conflitos de interesses entre estes e o principal. A busca pela maximização do desempenho organizacional ocasiona o estabelecimento de contratos, em que o principal proporciona alguns incentivos ao agente. Contudo, os níveis de significância encontrados para a correlação entre essas variáveis apontaram para a inexistência de correlação entre a remuneração e alguns dos indicadores de desempenho selecionados para a pesquisa, confirmando-se a relevância e a necessidade de continuidade dos estudos sobre o tema, uma vez que, em razão da separação da propriedade e controle e dos consequentes conflitos de agência entre proprietários e gestores, as empresas precisam adotar mecanismos para que o alinhamento entre esses agentes possibilite a criação de oportunidades que possam potencializar seus resultados.

Considerando-se as limitações da pesquisa, em especial quanto ao número de empresas estudadas e aos indicadores de desempenho selecionados, recomenda-se uma nova avaliação, na qual se leve em conta um grupo maior de empresas, inclusive com ações negociadas em bolsas estrangeiras, e distintos indicadores de desempenho, para que se possa analisar influências socioeconômicas diferentes.

\section{REFERÊNCIAS}

Aguiar, A. B., \& Pimentel, R. C. (2017). Remuneração de executivos e desempenho no mercado brasileiro: relações contemporâneas e defasadas. Revista de Administração Contemporânea, $21(4), 545-568$.

Almeida, R. S., Klotzle, M. C., \& Figueiredo, A. C., Pinto. (2013). Composição do conselho de administração no setor de energia elétrica do Brasil. Revista de Administração da Unimep-Unimep Business Journal, 11 (1), 156-180. 
Andreas, J. M., Rapp, M. S., \& Wolff, M. (2012). Determinants of director compensation in two-tier systems: evidence from German panel data. Review of Managerial Science, 6(1), 33-79.

Anjos, L. C. M., Tavares, M. F. N., Monte, P. A., \& Lustosa, P. R. B. (2015). Relações entre controle acionário e remuneração de executivos. Enfoque: Reflexão Contábil, 34 (1), 45-56.

Anthony, R. N., \& Govindarajan, V. (2008). Sistemas de controle gerencial. São Paulo: McGraw-Hill.

Beuren, I. M., Silva, M. Z., \& Mazzioni, S. (2014). Remuneração dos executivos versus desempenho das empresas. Revista de Administração Faces Journal, 13(2), 8-25.

Brealey, R. A., Myers, S. C., \& Allen, F. (2011). Principles of corporate finance. (10th ed.). New York: McGraw-Hill/Irwi.

Camargos, M. A., \& Helal, D. H. (2007). Remuneração executiva, desempenho econômico-financeiro e a estrutura de governança corporativa de empresas brasileiras. Anais do Encontro da Associação Nacional de Pós-Gradvação e Pesquisa em Administração, Rio de Janeiro, RJ, 31.

Conyon, M. J., \& Murphy, K. J. (2000). The prince and the pauper? CEO pay in the United States and United Kingdom. The Economic Journal, $110(467), 640-671$.

Degenhart, L., Martins, D. L. C. C., \& Hein, N. (2017). Desempenho econômico-financeiro e remuneração dos diretores executivos das empresas brasileiras. Enfoque Reflexão Contábil, 36(3), 118-135.

Demsetz, H., \& Villalonga, B. (2001). Ownership structure and corporate performance. Journal of corporate finance, 7(3), 209-233.

Eulerich, M., \& Velte, P. (2014). Determinants of executive board remuneration. Corporate Ownership \& Control, $11(4), 96-113$.

Fama, E., \& Jensen, M. (1983). Separation of ownership and control. Journal of Law and Economics, (26), 301-327.

Fávero, L. P., Belfiore, P., Silva, F. L., \& Chan, B. L. (2009). Análise de dados: modelagem multivariada para a tomada de decisões. Rio de Janeiro: Campus.

Ferrarini, G., \& Moloney, N. (2005). Executive remuneration in the EU: the context for reform. Oxford Review of Economic Policy, 21 (2), 304-323.

Forti, C. A. B., Barboza, F. L. M., Ribeiro, K. C. S., \& Nogueira, S. G. (2018). O Impacto do incentivo aos funcionários nos lucros dos bancos brasileiros. Enfoque Reflexão Contábil, 37(2), 51-66. 
Funchal, J. A., \& Terra, P. R. S. (2006). Remuneração de executivos, desempenho econômico e governança corporativa: um estudo empírico em empresas latino-americanas. Anais do Encontro da Associação Nacional de Pós-Graduação e Pesquisa em Administração, Salvador, BA, 30.

Gonzaga, R. P., Yoshinaga, C. E., \& Eid, W., Jr. (2013). Relação entre os sistemas de incentivos oferecidos aos gestores e desempenho das empresas brasileiras. Revista Contabilidade Vista \& Revista, $24(3), 103-118$.

Himmelberg, C. P., Hubbard, R. G., \& Palia, D. (1999). Understanding the determinants of managerial ownership and the link between ownership and performance. Journal of financial economics, 53(3), 353-384.

Instrução CVM n. 480. (2009). Retirado de http://www.bmfbovespa.com.br/empresas/download/ InstrucaoCVM480.pdf

Jensen, M. C., \& Meckling, W. H. (1976). Theory of the firm: managerial behavior, agency costs, and ownership structure. Jounal of Financial Economics, 3(4), 305-360.

Klein, B. (1984). Contract costs and administered prices: an economic theory of rigid wages. The American Economic Review, 74(2), 332-338.

Machado, D. G., \& Beuren, I. M. (2015). Política de remuneração de executivos: um estudo em empresas industriais brasileiras, estadunidenses e inglesas. Gestão \& Regionalidade, 31 (92), 4-24.

Marcon, R., \& Godoi, C. K. (2004). Desempenho financeiro das empresas e remuneração por stock options: um estudo multissetorial. Revista de Administração FACES Journal, 3(1), 59-76.

Nascimento, C., Franco, L. M. G., \& Cherobim, A. P. M. S. (2012). Associação entre remuneração variável e indicadores financeiros: evidências do setor elétrico. Revista Universo Contábil, 8(1), 22-36.

Nascimento, E. M., Barbosa, J. E., Cunha, J. V. A., Neto, \& Dias, W. O. (2011). Teoria da agência e remuneração de executivos: influência do uso de stock options no desempenho das empresas brasileiras. Anais do Congresso USP de Controladoria e Contabilidade, São Paulo, SP, 11.

Oliveira, I. G. S., \& Silva, A., Jr. (2018). Determinantes econômicos do uso de stock options em companhias brasileiras de capital aberto. Enfoque Reflexão Contábil, 37(1), 55-70.

Parente, P. H. N., Vasconcelos, A. C., \& De Luca, M. M. M. (2014). Influência da estrutura de propriedade horizontal e da estrutura de propriedade piramidal na governança das maiores empresas de capital aberto do Brasil. Anais do Congresso USP de Controladoria e Contabilidade, São Paulo, SP, 14. 
Rodrigues, J., \& Seabra, M. (2011). An analysis of corporate board compensations in the Portuguese energy sector. Management of Environmental Quality: An International Journal, 23(1), 56-67.

Rossetti, J. P., \& Andrade, A. (2014). Governança corporativa: Fundamentos, desenvolvimento e tendências. (7th ed.). São Paulo: Atlas.

Souza, P. V. S., Cardoso, R. L., \& Vieira, S. S. C. (2017). Determinantes da Remuneração dos Executivos e sua Relação com o Desempenho Financeiro das Companhias. REAd. Revista Eletrônica de Administração [Edição especial]. 234-228.

Teixeira, J. C. A., \& Loiola, E. (2006). Práticas inovadoras de gestão de pessoas e desempenho organizacional no Brasil. Anais do Encontro da Associação Nacional de Pós-Graduação e Pesquisa em Administração, Salvador, BA, 30.

Theiss, V., \& Beuren, I. M. (2014). O acionista controlador e a remuneração dos executivos nas empresas listadas na BM\&FBOVESPA. Revista de Gestão dos Países de Língua Portuguesa, 13(1), 2-13.

Toms, S., \& Wright, M. (2002). Corporate governance, strategy and structure in British business history, 1950-2000. Business History, 44 (3), 91-124.

\section{Como citar este artigo:}

ABNT

SILVA, Régis Barroso et al. Remuneração dos executivos e indicadores de desempenho em empresas participantes do Ibovespa. RACE, Revista de Administração, Contabilidade e Economia, Joaçaba: Ed. Unoesc, v. 17, n. 3, p. 867-888, set./dez. 2018. Disponível em: <http://editora.unoesc. edu.br/index.php/race>. Acesso em: dia/mês/ano.

APA

Silva, R. B., Silva, D. S. de C., De Luca, M. M. M., \& Vasconcelos A. C. de (2018). Remuneração dos executivos e indicadores de desempenho em empresas participantes do Ibovespa. RACE, Revista de Administração, Contabilidade e Economia, 17(3), 867-888. Retirado de http://editora. unoesc.edu.br/index.php/race 
